\title{
CRANIAL DIFFUSION-MRI INTERPRETATION: COMPARISON OF EMERGENCY MEDICINE AND RADIOLOGY RESIDENTS
}

\author{
Ferdi Kala ${ }^{1} \oplus$, Kurtulus Aciksari ${ }^{2}$ (] \\ ${ }^{1}$ Kahramanmaraş Necip Fazıl State Hospital Emergency Department, Kahramanmaraş, Turkey \\ ${ }^{2}$ Istanbul Medeniyet University Emergency Medicine Department, Istanbul, Turkey
}

\begin{abstract}
INTRODUCTION: Today diagnosis and treatment of ischaemic stroke is based on cranial CT and MR. The aim of this study is to measure the ability of emergency medical and radiology resident physicians to evaluate brain diffusion MRI and to provide better and faster recognition of the vital condition of acute ischaemic cerebrovascular infarct patients.
\end{abstract}

MATERIAL AND METHODS: 10 radiology and 10 emergency medicine residents were enrolled in the study. Of the 50 brain diffusion MRIs interpreted by trainees, 3 were normal, 13 had cerebral infarct, 27 had lacunar infarct, 3 had brain mass, 2 had hypoxic-ischaemic encephalopathy, 1 had MS and 1 had dermoid cyst. Each participant evaluated 50 digital diffusion MR images sequentially. They were asked to indicate whether there was a pathological lesion on the images, if the lesion was acute or chronic, what was the localization of the lesion, and ultimately the possible preliminary diagnosis.

RESULTS: Experienced radiology resident physicians are found to be more accurate in determining MR results in comparison to their inexperienced colleagues in cerebral and lacunar infarcts $(p<0.01)$ but for noninfarct images, no difference was found between two groups $(p>0.05)$. Radiology residents outperformed emergency residents in both cerebral and lacunar infarct and non-infarct images $(p<0.01)$.

CONCLUSIONS: In the study authors' opinion training and education is a must for MRI interpretation for emergency residents which might be vital for ischaemic cerebrovascular patients.

KEY WORDS: magnetic resonance imaging; emergency medicine; medical education

Disaster Emerg Med J 2019; 4(3): 98-101

\section{INTRODUCTION}

Stroke is known as an acute onset of a neurological deficit due to an afocal injury to the central nervous system by a vascular consequence. Today, the diagnosis of stroke is based on the physical examination of the patient and radiological imaging methods. The most important step after the anamnesis and neurological examination is to confirm the clinical pre-diagnosis and detect the injured brain area for determining the best treatment approach. The diagnostic methods used for this purpose are Cranial Computed Tomography (CT) and Diffusion Cranial weighted Magnetic Resonance (DW-I MR) imaging. The initial evaluation of cranial CT and diffusion MRI for preliminary diagnosis of cerebrovascular disease is usually done by emergency medicine clinicians and due to emergency room overcrowding and the need for immediate decision, there is often not plen- 
ty of time for emergency physician to evaluate the imaging with the radiologist and the treatment plan is usually determined according to the interpretation by the emergency physicians [1]. Early diagnosis has become exceptionally important after determination of the effectiveness of thrombolytic or interventional treatment to be started in the first several hours after the onset of neurological findings in patients with the diagnosis of stroke [2]. The Diagnosis of stroke is a crucial part of emergency physician training and both radiology and emergency medicine trainees should be able to interpret MRI's of the patients timely and in precise manner.

The aim of this study is to measure the ability of emergency medical and radiology resident physicians to evaluate brain diffusion MRI and to provide better and faster recognition of the vital condition of CVD for patients.

\section{MATERIAL AND METHODS}

After the approval of the ethics committee of a Training and Research Hospital Emergency Medicine Clinic, 50 brain diffusion MR images compiled from the PACS archive of Radiology Clinic were used. Of the 50 brain diffusion MRIs interpreted by trainees, 3 were normal, 13 had cerebral infarct, 27 had lacunar infarct, 3 had brain mass, 2 had hypoxic-ischaemic encephalopathy, 1 had MS and 1 had dermoid cyst. Digital diffusion MR images were compiled in mixed order, deleting patients' names and other information and numbered from 1 to 50. A folder was created in which the image number and clinical diagnosis were recorded. Figure 1 details the images shown to the participants ten radiology and ten emergency medicine residents were enrolled in the study. Each participant evaluated 50 digital diffusion MR images sequentially.

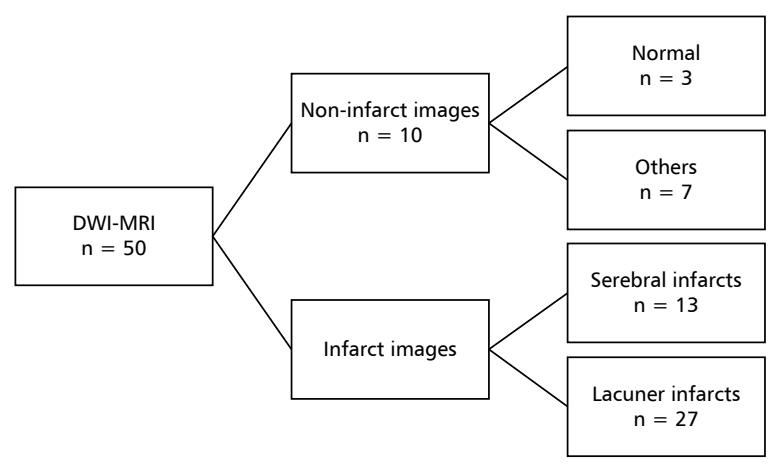

FIGURE 1. Distribution of Images shown to participants
The participants were blinded. Emergency residences were not trained prior to study on MRI interpretation. They were asked to indicate whether there was a pathological lesion on the images, if the lesion was acute or chronic, what was the localization of the lesion, and ultimately the possible preliminary diagnosis. NCSS (Number Cruncher Statistical System) 2007 (Kaysville, Utah, USA) program was used for statistical analysis. Pearson's chi-squared test, Fisher's exact test and Yates $\mathrm{P}$ continuity correction test were used to compare qualitative data as well as descriptive statistical methods. Significance was evaluated at $p<0.05$. The first- and second-year residents were classified as inexperienced and the third- and fourthyear residents were classified as experienced.

\section{RESULTS}

Performances of all physicians who participated in the study are shown in Table 1 and Table 2.

Experienced radiology resident physicians are found to be more accurate in determining MR results in comparison to their inexperienced colleagues in cerebral and lacunar infarcts $(p<0.01)$ but for non-infarct images, no difference was found between two groups ( $p>0,05)$. Radiology residents outperformed emergency residents in both cerebral and lacunar infarct and non-infarct images $(p<0.01)$. Experienced emergency physicians performed better than their juniors in cerebral, lacunar infarct images $(p<0.01)$. Correct response rates of non-infarct diffusion MR images of emergency medicine and radiology resident physicians do not differ statistically according to seniority $(p>0,05)$. The rate of correct answers given by experienced radiology assistant physicians to lacunar infarct images was statistically higher than inexperienced radiology assistant physicians $(p<0.01)$.

\section{DISCUSSION}

Diagnosis of cerebral infarction is challenging for clinicians. For example, in the study of Savits et al., it was stated that CT and MRI examinations can be found false negative by emergency department physicians especially in the evaluation of cerebellar infarctions [3].

Since clinicians have to evaluate the radiographs and decide the treatment, especially in emergency units, many studies have been done comparing the cranial imaging interpretation skills of physicians in these branches with radiologists [4]. Brain diffusion 


\begin{tabular}{|c|c|c|c|c|c|c|c|c|c|c|c|}
\hline & ๑ & बa & \begin{tabular}{l}
$*$ \\
\multirow{2}{*}{} \\
8 \\
8 \\
0 \\
0
\end{tabular} & & 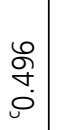 & & $\begin{array}{l}* \\
{ }^{*} \\
8 \\
0 \\
8\end{array}$ & & \begin{tabular}{l}
\multirow{1}{*}{} \\
0 \\
0 \\
0
\end{tabular} & & \\
\hline 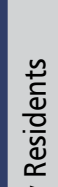 & 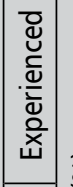 & ๖ & 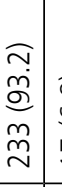 & 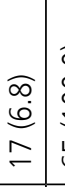 & 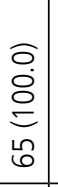 & $\begin{array}{l}\widehat{\partial} \\
\dot{\theta} \\
\dot{0}\end{array}$ & 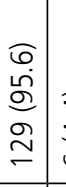 & $\begin{array}{l}\underset{J}{ナ} \\
\underset{\Xi}{\sigma}\end{array}$ & $\begin{array}{l}a \\
o \\
\infty \\
\stackrel{0}{0} \\
\sigma \\
m\end{array}$ & 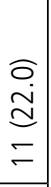 & \\
\hline $\begin{array}{l}\frac{0}{0} \\
\frac{\mathrm{O}}{\pi} \\
\approx 0\end{array}$ & 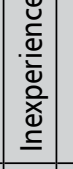 & & 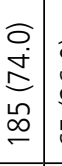 & 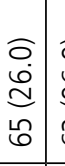 & 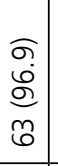 & $\begin{array}{c}\underset{C}{\stackrel{c}{m}} \\
\sim\end{array}$ & $\begin{array}{l}2 \\
0 \\
0 \\
\tilde{\sigma} \\
\sigma\end{array}$ & $\begin{array}{l}\widehat{\sigma} \\
\bar{m} \\
m \\
m\end{array}$ & $\begin{array}{l}\overrightarrow{0} \\
\dot{0} \\
0 \\
\dot{m}\end{array}$ & $\begin{array}{l}0 \\
\dot{0} \\
\dot{y} \\
o \\
i\end{array}$ & \\
\hline $\begin{array}{l}\overline{\widetilde{J}} \\
\stackrel{0}{\circ}\end{array}$ & & $\begin{array}{c}\stackrel{\varrho}{c} \\
\subseteq\end{array}$ & $\begin{array}{l}0 \\
\sigma \\
\dot{m} \\
\infty \\
\infty \\
\sigma \\
\sigma\end{array}$ & $\begin{array}{l}\underset{f}{\sigma} \\
\stackrel{\sigma}{\sigma} \\
\tilde{D} \\
\infty\end{array}$ & $\begin{array}{l}\text { ñ } \\
\infty \\
\stackrel{0}{0} \\
\infty \\
\simeq\end{array}$ & $\underset{\substack{n \\
\sim}}{\sim}$ & $\begin{array}{l}\sigma \\
\bar{\infty} \\
\bar{\alpha} \\
\bar{\sim}\end{array}$ & 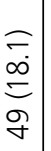 & $\begin{array}{l}0 \\
0 \\
0 \\
0 \\
0\end{array}$ & $\begin{array}{l}\bar{\partial} \\
\dot{m} \\
\bar{m} \\
\bar{m}\end{array}$ & \\
\hline$\frac{n}{\tilde{c}}$ & ○ & 仓) & 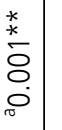 & & 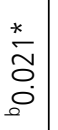 & & $\begin{array}{l}{ }^{*} \\
\overline{8} \\
0 \\
0 \\
0\end{array}$ & & $\begin{array}{l}0 \\
6 \\
0 \\
0\end{array}$ & & \\
\hline 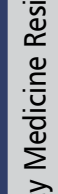 & 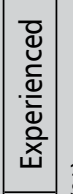 & ¿ & 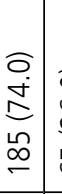 & $\begin{array}{l}0 \\
0 \\
\dot{d} \\
\tilde{d} \\
\tilde{b}\end{array}$ & $\begin{array}{l}10 \\
\infty \\
o \\
o \\
\mathbb{0}\end{array}$ & 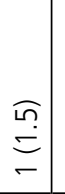 & 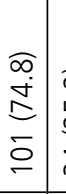 & $\begin{array}{l}\widehat{\widetilde{a}} \\
\stackrel{d}{d} \\
\stackrel{m}{m}\end{array}$ & $\begin{array}{l}0 \\
\dot{0} \\
\dot{y} \\
\dot{v} \\
\dot{v}\end{array}$ & $\begin{array}{l}0 \\
\dot{0} \\
0 \\
0 \\
m\end{array}$ & \\
\hline 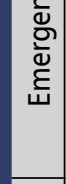 & 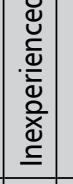 & $=$ & 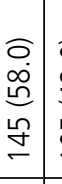 & 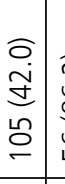 & 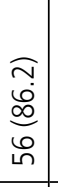 & 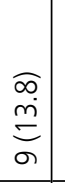 & $\begin{array}{l}\widehat{m} \\
\tilde{n} \\
\stackrel{n}{N} \\
\mathbb{N}\end{array}$ & $\begin{array}{l}\hat{\sigma} \\
\dot{0} \\
\hat{y} \\
\tilde{0}\end{array}$ & $\begin{array}{l}\vec{o} \\
\dot{p} \\
\stackrel{m}{c} \\
\underline{\sigma}\end{array}$ & $\begin{array}{l}0 \\
\dot{\theta} \\
\dot{b} \\
m \\
m\end{array}$ & \\
\hline $\begin{array}{l}\overline{\text { त्ञ }} \\
\text { مِ }\end{array}$ & & $\stackrel{\circ}{\stackrel{\circ}{c}}$ & \begin{tabular}{l|l}
0 & \\
$\dot{0}$ & \\
0 & \\
0 & \\
0 & \\
$m$ & $\vdots$
\end{tabular} & 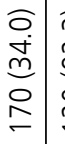 & $\begin{array}{l}\widehat{m} \\
\tilde{\sigma} \\
\stackrel{ }{\simeq}\end{array}$ & $\begin{array}{l} \\
\mathbb{a} \\
\stackrel{1}{0} \\
\end{array}$ & 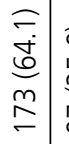 & $\begin{array}{l}\sigma \\
\stackrel{n}{n} \\
\stackrel{n}{n} \\
\sigma\end{array}$ & 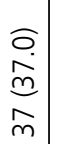 & $\begin{array}{l}\hat{\partial} \\
\hat{m} \\
\hat{\tilde{m}} \\
\hat{0}\end{array}$ & 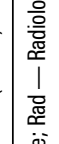 \\
\hline & e & $\begin{array}{l}\stackrel{\circ}{e} \\
c\end{array}$ & 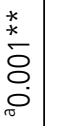 & & $\begin{array}{l}\stackrel{*}{\circ} \\
\tilde{\nu} \\
0 \\
0\end{array}$ & & \begin{tabular}{l}
$*$ \\
\multirow{2}{*}{} \\
$\delta$ \\
0 \\
0
\end{tabular} & & $\begin{array}{l}{ }^{*} \\
{ }^{*} \\
\overline{8} \\
0 \\
0\end{array}$ & & 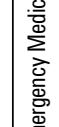 \\
\hline$\overline{\breve{c}}$ & $\begin{array}{l}\substack{\pi \\
\propto \sim} \\
\end{array}$ & ¿ & $\begin{array}{l}\sigma \\
\dot{\omega} \\
\dot{\infty} \\
\infty \\
\infty \\
\dot{\sigma} \\
\dot{\sigma}\end{array}$ & 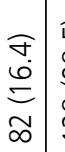 & $\begin{array}{l}\widetilde{\Omega} \\
\infty \\
\stackrel{0}{0} \\
\infty \\
\stackrel{\simeq}{\simeq}\end{array}$ & $\underset{\sim}{\stackrel{n}{\Xi}}$ & $\begin{array}{l}\bar{\sigma} \\
\bar{\infty} \\
\bar{ָ}\end{array}$ & $\begin{array}{l}\underset{\infty}{\infty} \\
\stackrel{\infty}{=} \\
\stackrel{9}{7}\end{array}$ & $\begin{array}{l}0 \\
0 \\
0 \\
0 \\
0 \\
0\end{array}$ & $\begin{array}{l}\frac{o}{\dot{m}} \\
\bar{m} \\
\bar{m}\end{array}$ & 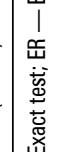 \\
\hline$\frac{\pi}{\bar{\omega}}$ & 孚 & $\mathrm{c}$ & 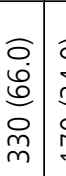 & 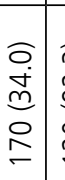 & $\begin{array}{l}\widetilde{m} \\
\widetilde{\jmath} \\
\stackrel{ }{\simeq}\end{array}$ & $\begin{array}{l}\hat{\Sigma} \\
\stackrel{5}{0} \\
0\end{array}$ & $\begin{array}{l}\vec{E} \\
\dot{d} \\
m \\
\Sigma \\
=\end{array}$ & $\begin{array}{l}\sigma \\
\text { n. } \\
\stackrel{n}{n} \\
\sigma\end{array}$ & 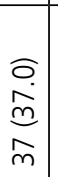 & 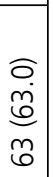 & 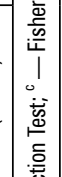 \\
\hline 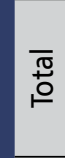 & & 仓) & 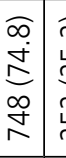 & 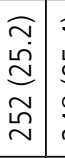 & $\begin{array}{l}\stackrel{\mho}{*} \\
\stackrel{\leftrightarrow}{O} \\
\stackrel{\infty}{\sim} \\
\stackrel{\sim}{\sim}\end{array}$ & $\begin{array}{l}\underset{0}{ \pm} \\
\stackrel{ \pm}{\simeq}\end{array}$ & 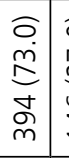 & 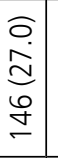 & 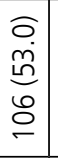 & 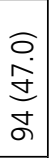 & 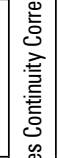 \\
\hline & & & 蒿 & \begin{tabular}{l}
0 \\
\multicolumn{1}{c}{} \\
$\vdots$ \\
$\sum^{2}$
\end{tabular} & $\begin{array}{l}\frac{\vec{L}}{\mathrm{~T}} \\
\frac{\mathrm{O}}{\mathrm{x}}\end{array}$ & $\begin{array}{l}\text { Dे } \\
\text { Dे } \\
\text { خे }\end{array}$ & 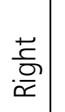 & $\begin{array}{l}\text { Dे } \\
\text { के }\end{array}$ & $\frac{+}{\frac{D}{x}}$ & $\begin{array}{l}0 \\
\overline{0} \\
\stackrel{0}{3}\end{array}$ & 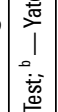 \\
\hline & & & 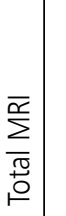 & & 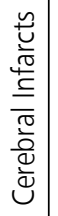 & & 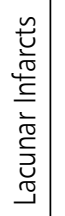 & & 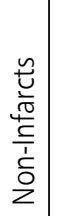 & & 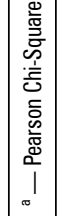 \\
\hline
\end{tabular}

Table 2. Evaluation of accurate interpretation
ratios according to infarct type
\begin{tabular}{|l|c|c|c|c|}
\hline \multirow{4}{*}{} & Total & \multicolumn{2}{|c|}{ Infarcts } & $\mathrm{p}$ \\
\cline { 2 - 5 } & & Cerebral & Lacunar & \\
\cline { 2 - 5 } & $\mathrm{n}(\%)$ & $\mathrm{n}(\%)$ & $\mathrm{n}(\%)$ & \\
\hline Right Answer & 642 & 248 & 394 & ${ }^{b} 0.001^{* *}$ \\
& $(80.3)$ & $(95.4)$ & $(73.0)$ & \\
\hline Wrong Answer & 158 & $12(4.6)$ & 146 & \\
& $(19.8)$ & & $(27.0)$ & \\
\hline b- Yates Continuity Correction Test & \\
\hline
\end{tabular}

MR images taken in emergency departments are often first evaluated by the emergency medicine clinician. Emergency department clinicians often plan their treatment according to their own assessments without the opportunity to discuss with the radiologist even in medical conditions that might be life-threatening and require urgent intervention [1].

In the literature, there are plentiful studies which compare emergency physicians and radiologists for accurate interpretation of CT's. In the study by Khoo et al. [5], the performance of emergency physicians was found to be insufficient and incorrect reporting was found in $1 / 3$ patients. This rate has been reported to be particularly high in patients with cerebral infarction in the elderly. In the study conducted by Alvaro [6] in the emergency medicine residency program, author found false positivity in $24.5 \%$ of 79 cerebral infarct patients. In a study by Alresi et al neuroradiologists and emergency medicine specialists were compared, and especially in the interpretation of lacunar infarct patients high levels of false-positive positivity of emergency medical doctors [7] Arentds [8]. In his study, which included both traumatic and internal interpretation of cranial $C T$, moderate discordant was found between emergency physicians and radiologists in general, but no discordant relationship was found between the experience of emergency physicians, meaning experience in the ED does not affect accuracy of $C T$ interpretation which might be explained by suboptimal interpretation conditions of emergency departments. In this study also performance of ED trainees was lower than radiology trainees in parallel to the presented study's results. The authors should underline that the presented study was performed in optimal conditions and training of residents is an important factor for interpreting results accurately as mentioned in other studies [9].

The presented study is one of the few studies in which Cranial DW-I MRI was evaluated in the 
literature by radiologists and emergency physicians. In the previous study, it was found that $14 \%$ of ischaemic strokes were missed by emergency medical physicians on Diffusion MRI imaging [10]. In this study, even cerebral infarcts which require immediate intervention and treatment were diagnosed better by radiology residents than emergency residents. Besides most of the images selected in this study were lacunar infarct cases that could be overlooked. According to the seniority of emergency medicine and radiology residents, the rate of recognition of lacunar infarcts was statistically significant. The fact that both branch residents distinguish the lacunar infarcts correctly in correlation to seniority supports the opinion that MR interpretation skills are gained during emergency medicine and radiology training.

When emergency medicine and radiology trainees were compared it is understood that radiology residents are superior in MR evaluation compared to emergency medical residents.

Emergency medicine residents correctly confirmed $73.2 \%$ of 400 images with acute infarction. While junior emergency medical residents know $64 \%$ of 200 images correctly; It was observed that senior emergency medical residents know $82.5 \%$ of 200 images correctly. In addition, the patient's emergency department physicians evaluate the brain diffusion MRI according to the patient's clinical findings; so it can be concluded that whenever the clinical status of the patient cannot be clarified even if any pathological lesion cannot be perceived in the imaging of patients presenting to the emergency department due to neurological symptoms; one should consult to neurology and radiology clinics before making a decision alone.

\section{LIMITATIONS}

Participants were selected from a single centre. The fact that the number of participants is higher in more centres adjusted for each seniority may increase the level of significance of the data. Participants evaluated brain diffusion MRIs in an isolated environment from the emergency department. The data in the evaluations to be made at the bedside and in the emergency room might be more meaningful.

\section{CONCLUSIONS}

MRI interpretations should be performed in accordance with radiologist while approaching ischaemic stroke patients by especially inexperienced emergency physicians. In residency training emergency departments should consider MRI interpretation courses or seminars where applicable.

\section{Acknowledments: None.}

\section{Conflict of interest: None.}

\section{REFERENCES}

1. Ferro JM, Pinto AN, Falcão I, et al. Diagnosis of stroke by the nonneurologist. A validation study. Stroke. 1998; 29(6): 1106-1109, doi: 10.1161/01.str.29.6.1106, indexed in Pubmed: 9626279.

2. Powers W, Derdeyn C, Biller J, et al. 2015 American Heart Association/ American Stroke Association Focused Update of the 2013 Guidelines for the Early Management of Patients With Acute Ischemic Stroke Regarding Endovascular Treatment. Stroke. 2015; 46(10): 3020-3035, doi: 10.1161/str.0000000000000074.

3. Savitz SI, Caplan LR, Edlow JA. Pitfalls in the diagnosis of cerebellar infarction. Acad Emerg Med. 2007; 14(1): 63-68, doi: 10.1197/j. aem.2006.06.060, indexed in Pubmed: 17200515.

4. Evans LR, Fitzgerald MC, Mitra B, et al. Emergency department interpretation of $\mathrm{CT}$ of the brain: a systematic review. Postgrad Med J. 2017; 93(1102): 454-459, doi: 10.1136/postgradmedj-2016-134491, indexed in Pubmed: 28011895.

5. Khoo NC, Duffy M. Out of hours non-contrast head CT scan interpretation by senior emergency department medical staff. Emerg Med Australas. 2007; 19(2): 122-128, doi: 10.1111/j.17426723.2007.00914.x, indexed in Pubmed: 17448097.

6. Alfaro D, Levitt MA, English DK, et al. Accuracy of interpretation of cranial computed tomography scans in an emergency medicine residency program. Ann Emerg Med. 1995; 25(2): 169-174, doi: 10.1016/s0196-0644(95)70319-5, indexed in Pubmed: 7832342.

7. Al-Reesi A, Stiell IG, Al-Zadjali N, et al. Comparison of CT head interpretation between emergency physicians and neuroradiologists. Eur J Emerg Med. 2010; 17(5): 280-282, doi: 10.1097/MEJ. Ob013e32833483ed, indexed in Pubmed: 20154626.

8. Arendts $G$, Manovel A, Chai A. Cranial CT interpretation by senior emergency department staff. Australas Radiol. 2003; 47(4): 368-374, doi: 10.1046/j.1440-1673.2003.01204.x, indexed in Pubmed: 14641187.

9. Dolatabadi A, Baratloo A, Rouhipour A, et al. Interpretation of Computed Tomography of the Head: Emergency Physicians versus Radiologists. Trauma Monthly. 2013; 18(2): 86-89, doi: 10.5812/ traumamon. 12023.

10. Oray D, Limon O, Ertan C, et al. Inter-Observer Agreement on Diffusion-Weighted Magnetic Resonance Imaging Interpretation for Diagnosis of Acute Ischemic Stroke Among Emergency Physicians. Turk J Emerg Med. 2015; 15(2): 64-68, doi: 10.5505/1304.7361.2015.32659, indexed in Pubmed: 27336066. 